\title{
Inheritance and Development of Chinese Aesthetic Spirit in Contemporary Art Design
}

\author{
Feili Gong, Qi Chen \\ Department of Media Nanchang Institute of Technology, Nanchang City Jiangxi Province, 330044
}

Keywords: Chinese aesthetic spirit; Contemporary art design; Inheritance; Development

\begin{abstract}
Aesthetics is an art about people's aesthetic relationship in reality. It not only has ancient traditional culture and long history, but also cutting-edge fashionable culture and innovative spirit. Chinese aesthetic spirit is the concentrated reflection of the inheritance and development of five thousand years of Chinese history. Chinese aesthetic spirit is inseparable in contemporary art design, and the inheritance and development of Chinese culture is an inevitable approach in contemporary art design. In this paper, the inheritance and development of Chinese aesthetic spirit in contemporary art design is studied, and the advancement of Chinese aesthetic spirit and its guiding role in contemporary art design are analyzed. On this basis, approaches of inheriting and developing Chinese aesthetic spirit in contemporary art design are discussed.
\end{abstract}

\section{Introduction}

Concerning contemporary art, general secretary $\mathrm{Xi}$ Jinping once pointed out clearly that "Excellent traditional Chinese culture is the lifeblood of Chinese nation, an important source of socialist core values as well as the basis for China to gain a firm foothold in global world cultures." With the rapid development of economy, reform and innovation also happen in the field of art. The number of Chinese aesthetic spirit keeps increasing in recent years, so to explore the inheritance and development of Chinese aesthetic spirit in contemporary art design is of great importance to the comprehensive improvement of contemporary art design.

\section{Chinese aesthetic spirit}

Chinese aesthetic spirit has been regarded as a new research hot topic in art and aesthetic researches, and it is a crystal from the continuous integration and collision between traditional Chinese culture and foreign culture. From philosophical perspective, Chinese aesthetic spirit has the profound intension of Chinese culture. It has plain yin and yang dialectical thoughts, thereby forming the unique yin-yang and five elements academic theory in the world. In Chinese aesthetic spirit, yin-yang and five elements academic theory has resulted to "Chinese thinking model" which is unique to Chinese descendants. No matter it is aesthetic habits or analysis and viewpoints on things, the aesthetic uniqueness of "Chinese thinking model" is always fully represented in Chinese aesthetic spirit. For example, in the creation of cultural art, emotional description is attached with more importance in traditional Chinese thinking model, and what Chinese aesthetic spirit pursues is the artistic conception of a certain art; however, substantiality is the creation premise in the West. Traditional Chinese artistic forms emphasize the emotional expression of subjects' inner world as well as the representation and implementation of one's own values and philosophical emotions in artistic forms, and it is an art representation form with strong subjectivity inclination. Therefore, from an objective perspective, the creation of all Chinese art, on the one hand, is the implementation of Chinese aesthetic spirit; on the other hand, deepens the understanding of Chinese aesthetic spirit.

To inherit and develop Chinese aesthetic spirit, the development history of characteristic art design aesthetics of Chinese nation needs to be organized and analyzed. There is no distinct proportion between the prosperous period of art and social development, and there is a certain 
unbalance appearance between material production and artistic creation; different material basis develops distinctively. This phenomenon is especially obvious in ancient China. In agricultural society with low production efficiency, productivity was low, population was huge, but China could maintain advanced standard in its art. Chinese society was a "prematurely aging" society. Its artistic standard and aesthetic spirit were distinctly higher than social production at that time. Artistic expression transformed from realistic painting to the period of high abstraction and signifying untimely. The source of this phenomenon is Chinese aesthetic spirit and the advancement of philosophical system. Ancient Chinese society based on yin-yang theory is a unique binary system society, in which emerged containment, strong vitality and all-embracing and absorbing confident posture not possessed by other culture. Waxing and waning of yin-yang in philosophical theoretical system, Tao and air of the Taoists, Confucian unity of heaven and man and other advanced philosophical intellectual enquiry system and lofty spiritual pursuits guide artistic design into the stage of spontaneous expression prematurely, while Western art did not break through the fence of realistic painting until Vincent van Gogh, which indeed had something to do with Western rigorous scientific inquiry thinking habits. However, art design is not entirely a process of rigorous rational thinking, it is more in need of the support from cultural connotation, philosophical thoughts and social background. Comparatively speaking, Chinese aesthetic spirit has indisputable advancement in its ideology and philosophical thought support.

Chinese art design aesthetic spirit and theory construction can differentiate Chinese contemporary art design from Western art design viewpoints and ideas, thereby exploring a contemporary art design practice road with Chinese characteristics. In his book Capitalism Cultural Contradiction, the well-known American scholar Daniel Bell said that "Capitalism culture is being replaced by hedonism gradually. Today, when liberalism is prevalent, cultural images begin to combine with modernism impulses. Impulsive pursuits are regarded as behavior standards, which is the ideology principle and the source of capitalism cultural contradiction and modernism dual trammels." In order to break through the ideology dilemma of modern art design, Chinese contemporary art design can look for wisdom in Chinese aesthetic spirit, implement the profound and unique Eastern aesthetics viewpoint and theoretical spirits of Chinese nation and open up a new road of contemporary art design which is different from Western art design creation theoretical history.

\section{Inheritance and development of Chinese aesthetic spirit in contemporary art design}

China is a nation with five thousand years of civilization development history. The coexistence of multiple nationalities leads to the unique artistic connotation and charm of Chinese national art. Because of the long history of China and the profound deposits of national culture and art, art design historical data and art works are as vast as the smoke and sea. Therefore, contemporary people need to discard the dross and select the essential, draw correct and advanced art design aesthetic viewpoints from the abundant art design works, confirm and represent traditional Chinese aesthetic characteristics, pay attention to realistic painting as well as Chinese art design aesthetic history of real demands. At present, some scholars and experts have made outstanding achievements in art design of new era. For example, in Design Philosophy of Chinese Design, Chinese design theories are organized comprehensively. The book provides an inspiring conclusion with golden-mouthed facts, i.e., ancient China had abundant design and creation practice; its advancement of design philosophy and design thoughts had risen to a high philosophical layer. Or, we can say that ancient China can rely on art design to express its philosophical belief, i.e., the so-called "my belief". Take the development of traditional Chinese graphic pattern for example. From the Neolithic Age, it has been through over 8000 years. The wide range of themes, the large number and excellent quality are rare in world decoration history. There are 300 color drawings of utensils and over 20000 utensil pattern rubbings and line drawings, which describe and summarize ancient Chinese patterns systemically. The collection of pattern involves multiple artistic forms, such as ceramics, bronze ware, jade ware, weaving, stone inscription, gold and silver ware, etc. Our predecessors have reached a high standard in researches of Chinese art design history. Standing on 
the shoulders of predecessors, contemporary scholars and researchers should devote more energy to the nationalization of Chinese art design.

Contemporary design is an important medium for Western aesthetic thoughts. When Chinese art designers are implementing Western aesthetic thoughts, they are confronted with cultural radicalism and cultural self-contempt. However, Chinese modern aesthetics was connected to Western aesthetics from the enlightenment period. In this process, Chinese art creators made a brief comparison between traditional Chinese aesthetic thoughts and Western aesthetic concepts as well as their categories. They acted in a Procrustean way and forced to include traditional Chinese aesthetic thoughts into Western art creation aesthetic system. However, we should notice that art communication between the West and East is never unidirectional. Eastern civilization at present is still weak. However, Eastern culture created far-reaching influences on Western design art in history. In the era of navigation, the impetus for Westerners to go to sea was the beautiful yearning for tea, ceramics and the Eastern world. No matter it is cultural radicalism or cultural self-contempt, they lost self-confidence to local national culture fundamentally. Therefore, to inherit and develop Chinese aesthetic spirit, we need to get rid of self-contempt to Chinese national civilization under the framework of Western art aesthetic spirt and free Chinese aesthetic spirit from Western aesthetic framework, thereby declaring the comprehensive awakening of Eastern world to the whole world loud and clear and confirming design creation aesthetic principles and humanistic spirit. Only in this way can Chinese contemporary art design walk on the right path.

Contemporary art design develops rapidly, design demands become more diversified, individuation becomes stronger, design forms become more diversified, design materials are more abundant, the integration trend between tradition and modernization and among different values is more obvious and the collision is fiercer. Contemporary art design should carry out art design practice under the fundamental principle and guidance of traditional Chinese aesthetic spirit during inheritance and development. The themes should be focused on development changes of Chinese modern society, time and livelihood, reality flowing and so on. Also, it should grasp the cultural lifeblood of Chinese nation and conform to the tide of contemporary art design. In art design and creation, we should establish and carry forward aesthetic confidence of traditional Chinese culture, pay attention to the development course of Chinese society and people's livelihood, thereby exploring Chinese art design aesthetic spirit and cultural qualities with Eastern aesthetic inclination in the conflict between Eastern aesthetic viewpoints and modern aesthetics.

\section{Conclusion}

Contemporary art design should confirm Chinese aesthetic spirit confidence sufficiently, face up to the advancement of traditional Chinese art design, establish aesthetic confidence and theoretical confidence gradually, conclude and analyze development law of Chinese art design from historical perspective, form design history perspective, aesthetic viewpoints and common viewpoints with Chinese characteristics, thereby laying solid basis for the comprehensive prosperity of Chinese art design. There is a large amount of reference values to modern art design in traditional Chinese culture and art, and the cultural symbols and content that can reflect the profound national wisdom are waiting to be further developed.

\section{References}

[1] Wang Hongbin, Li Yisong. Research on Approaches for the Inheritance and Development of Chinese Aesthetic Spirit and Art Spirt [J]. Journal of Zhengzhou University of Light Industry (Social sciences edition), 2016(06).

[2] Tao Shuiping. Deepening Art Aesthetic Researches Carrying Forward Chinese Aesthetic Spirit [J]. Journal of Jiangxi Normal University. (Philosophy social sciences edition), 2015(03).

[3] Chu Xiaoqing. Influences on Art Creation Values and Aesthetic Value-orientation from Technological Progress [J]. Various Schools for Art, 2016(01). 
[4] Li Dongning, Li Jian. Inheritance and Development of Chinese Aesthetic Spirit in Contemporary Art Design [J]. Various Schools for Art, 2016(04).

[5] Wang Hongbin. Eastern Luxury Consumption and British Society in the 18th Century from the Perspective of Global History [J]. Journal of Henan Normal University (Philosophy social sciences edition), 2012(6):147-149

[6] Zhang Yuneng, Zhang Gong. Socialism with Chinese Characteristics Aesthetics Carrying Forward Chinese Aesthetic Spirit [J]. Beauty and Time (II) ,2015(01).

[7] Zhang Han. Contemporary Global Significance of Inheriting and Developing Chinese Aesthetic Spirit [J]. Beauty and Time (II) ,2015(05)

[8] Cheng Zhongxiang. Inheriting and Developing Chinese Aesthetic Spirit and Contemporary Art [J]. Journal Zhejiang Vocational Academy of Art,2015(03). 